\title{
Homozygous SOD1 Variation L144S Produces a Severe Form of Amyotrophic Lateral Sclerosis in an Iranian Family
}

Delia Gagliardi, MD, Minoo Ahmadinejad, MD, Roberto Del Bo, BS, Megi Meneri, MD, PhD, Giacomo Pietro Comi, MD, Stefania Corti, MD, PhD, and Dario Ronchi, PhD

Neurol Genet 2022;8:e645. doi:10.1212/NXG.0000000000000645

\section{Abstract}

\section{Objectives}

Amyotrophic lateral sclerosis (ALS) is a devastating neurodegenerative disorder characterized by degeneration of motor neurons determining progressive muscular atrophy, weakness, and death from respiratory failure.

\section{Methods}

Here, we report clinical and molecular findings of a novel Iranian family affected with a severe form of early-onset familial ALS.

\section{Results}

Three siblings born to consanguineous parents developed a form of ALS characterized by earlyonset lower limb involvement and a fast progression, proving fatal at age 16 years for 1 of them. Molecular analysis of the SOD1 gene revealed the homozygous substitution c.434T >C in exon 5 resulting in the amino acid change p.Leu144Ser (L144S), previously reported as a dominant variant. Both parents were heterozygous carriers. The probands' mother recently developed a late-onset ALS with predominant upper motor neuron involvement.

\section{Discussion}

This report adds p.L144S to the short list of homozygous SOD1 variants and suggests that the development of an earlier-onset and/or faster disease progression can occur when 2 mutated alleles are present.

From the Neuroscience Section, Dino Ferrari Centre, Department of Pathophysiology and Transplantation (DEPT) (D.G., R.D.B., G.P.C.,S.C., D.R.), University of Milan, Italy; Neurology Unit (D.G., M.M., S.C., D.R.), Foundation IRCCS Ca' Granda Ospedale Maggiore Policlinico, Milan, Italy; Blood Transfusion Research Center (M.A.), High Institute for Research and Education in Transfusion Medicine, Tehran, Iran; Neuromuscular and Rare Diseases Unit, Department of Neuroscience (G.P.C.), Fondazione IRCCS Ca' Granda Ospedale Maggiore Policlinico, Milan, Italy.

Go to Neurology.org/NG for full disclosures. Funding information is provided at the end of the article. 
A

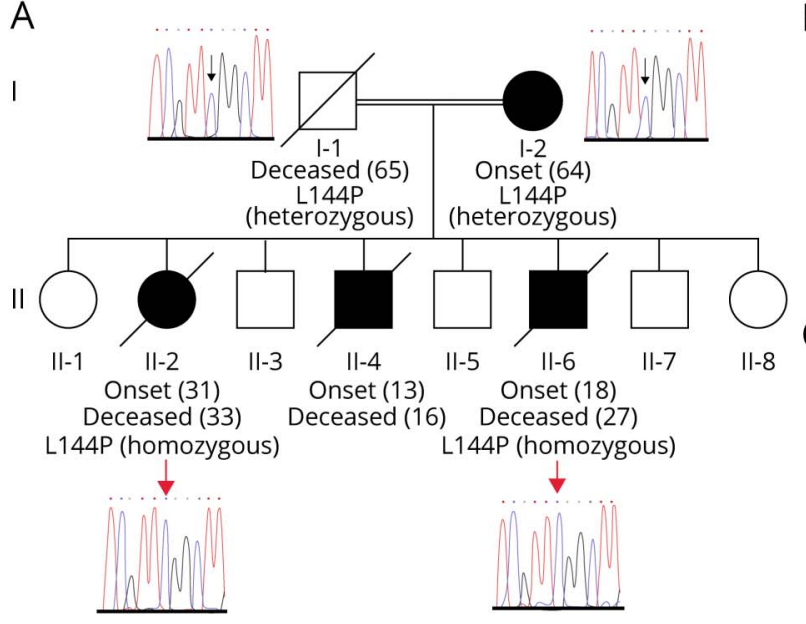

B

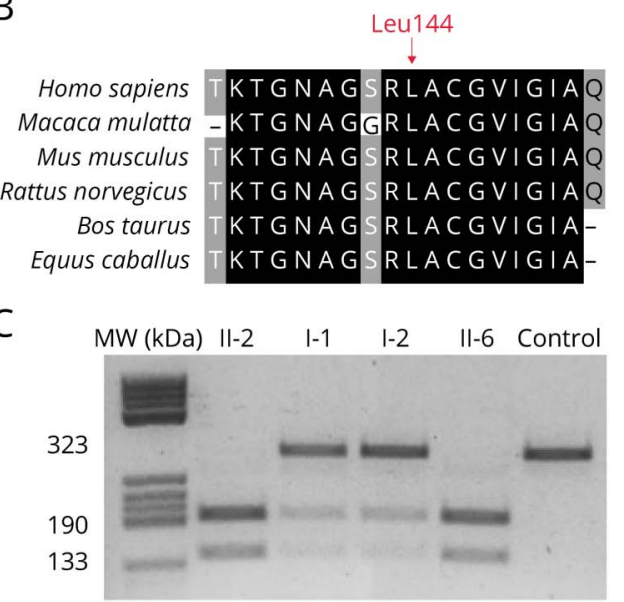

(A) Electropherograms shown the homozygous c.434T>C SOD1 variant in two affected siblings (black symbols II-2 and II-6), whereas their consanguineous parents (I-1 and I-2) are heterozygous carriers. Black symbols indicate affected patients. Age at symptom onset, age at death, and SOD1 genotype for patients who underwent genetic testing are indicated. (B) Partial SOD1 protein sequence alignment among different species. Affected residue is a well-conserved amino acid (leucine 144). (C) PCR-RFLP analysis of c.434T>C variant in members of the family whose DNA was available. Xmnl endonuclease cuts mutated molecules producing two bands of 190 and $133 \mathrm{bp}$, whereas wild-type amplicons remain uncut.

More than 200 variants in the SOD1 gene, encoding a copperzinc superoxide dismutase, have been found in patients with familial amyotrophic lateral sclerosis (fALS) and patients with sporadic ALS (sALS) (alsod.iop.kcl.ac.uk/Als/index.aspx), and most of them are dominantly inherited. ${ }^{1,2}$

Only 6 SOD1 variants (L84F, N86S, D90A, L117V, L126S, and G27delGGACCA) have been so far reported as homozygous changes in patients with fALS, but a recessive inheritance was demonstrated only for few of them. In this regard, the D90A mutation is known to exhibit a pathogenetic behavior according both dominant and recessive modes of inheritance. ${ }^{2,3}$

Here, we disclosed the c.434T >C (p.L144S) SOD1 variant in an Iranian family presenting a severe early-onset form of ALS. The mutation was previously reported in heterozygosis in patients with fALS and sALS, sharing lower limb onset, a relative benign course, and long survival time. Notably, the affected individuals in our pedigree displayed c.434T $>\mathrm{C}$ in homozygous state, whereas their mother, heterozygous carrier of the mutation, developed ALS symptoms at a later age.

\section{Case Report}

The probands (patients II-2 and II-6) are 2 Iranian siblings born from consanguineous parents (Figure, A). A third affected member (II-4 in pedigree) was the first child to develop symptoms of ALS at age 13 years and died at age 16 years after a rapid disease progression. Proband II-2 clinical manifestations started at age 31 years (after the delivery of the second child) with paresthesia of her toes and progressed rapidly with painful weakness of upper and lower extremities in 1 year, followed by dysarthria and dysphagia, and leading to death at age 33 years.
Patient II-6 presented at age 18 years with gait disturbance due to lower limb weakness and progressed within 9 years with upper limb weakness, dysphagia, and respiratory failure requiring tracheostomy. He died at age 27 years. Several years later, at age 64 years, the probands' mother started developing a proximal, hypertonic, and asymmetric weakness, predominant in lower limbs, causing diffculty in rising from the sitting position and climbing stairs, followed by ataxia and lower limb numbness. EMG-NCV and MEP showed signs suggestive of ALS with prevalent upper motor neuron (UMN) involvement. She is currently 65 years of age. The father died at age 65 years from causes unrelated to ALS. Written informed consent was obtained from all participants in the study.

Molecular analysis of the SOD1 gene in patients II-3 and II-7 revealed the homozygous substitution c.434T>C in exon 5 resulting in the amino acid change p.Leu144Ser. Both parents were heterozygous carriers (Figure, A). DNA from patient II- 5 and from unaffected siblings was not available for molecular testing. Leucine at position 144 is highly conserved across species (Figure, B) and takes part in an active loop comprising the SOD1 active center. The variant was confirmed by PCR-RFLP analysis (Figure, C).

\section{Discussion}

The L144S SOD 1 variant has been initially described in 2 fALS relatives presenting an early onset (mean $=42.5$ years) and an unusual prolonged survival ( 9 and 13 years). ${ }^{4} \mathrm{~A}$ mutational screening performed on 60 ALS Iranian patients identified SOD1 mutations in $11.7 \%$ of the cohort, and the heterozygous L144S mutation was found in 2 siblings and in an sALS case. All of them displayed initial lower limb involvement, early disease onset ( 28 and 27 years in fALS and 45 years in sALS) and extended survival (still alive after an average of 10 years). ${ }^{5}$ 
Early age at onset and a slow progression with extended survival were also observed in 3 Brazilian and in 8 Polish patients with ALS carrying this variant. ${ }^{6,7} \mathrm{~L} 144 \mathrm{~S}$ is the second most frequent SOD1 variant among patients with ALS in Poland and has been proposed to derive from a founder allele. ${ }^{7}$ A change in the same codon (p.L144F) also displayed incomplete penetrance, lower limb onset, and variable progression, supporting the importance of the conserved codon 144 .

In this report L144S occurs in homozygous state in 2 affected siblings of an Iranian family presenting early-onset and fast progressive ALS. The more severe phenotype observed in the probands could be explained by the presence of 2 mutated alleles. The probands' mother, who carried the variant in heterozygous state, had a later disease onset with predominant UMN involvement. This finding rules out a recessive disease inheritance in this pedigree. Because the probands' father died at age 65 years, it could be supposed that he was a presymptomatic carrier. However, incomplete penetrance cannot be excluded.

The L144S variant has been previously identified in 4 asymptomatic individuals ( 2 of them younger than 45 years), ${ }^{7}$ suggesting incomplete penetrance. On the other hand, we can speculate on the existence of genetic modifiers, partially protecting the heterozygous carriers and slowing disease onset in the parents.

In conclusion, we described a familial form of ALS due to L144S SOD1 variant presenting both in heterozygous and homozygous fashion in the affected members. The older age at onset and the disease phenotype in the heterozygous patient resemble the previous reported cases, whereas the occurrence of the L144S variant in homozygous state results in a more severe and fast progressive disease.

This report may add a piece of knowledge in the comprehension of SOD1-related ALS pathogenesis, and it is also relevant for therapeutics development with SOD1 antisense strategy approaching to clinical use.

\section{Data Availability}

Anonymized data not published within this article will be made available by request from any qualified investigator.

\section{Acknowledgment}

Gratitude has to be expressed to the patient for participating in this research. The authors thank "Associazione Amici del Centro Dino Ferrari” for its support. GPC and SC are members of the European Reference Network for Rare Neuromuscular Diseases (ERN EURO-NMD).

\section{Study Funding}

This study received support by grant CP 20/2018 (Care4NeuroRare) from Fondazione Regionale per la Ricerca Biomedica (FRRB) to SC and by Italian Ministry Foundation IRCCS Cà Granda Ospedale Maggiore Policlinico Ricerca Corrente 2020 to GC.

\section{Disclosure}

The authors report no disclosures relevant to the manuscript. Go to Neurology.org/NG for full disclosures..

\section{Publication History}

Received by Neurology: Genetics July 15, 2021. Accepted in final form October 15, 2021.

Appendix Authors

\begin{tabular}{lll}
\hline Name & Location & Contribution \\
\hline $\begin{array}{l}\text { Delia } \\
\text { Gagliardi, MD }\end{array}$ & $\begin{array}{l}\text { Neuroscience Section, Dino } \\
\text { Ferrari Centre, Department } \\
\text { of Pathophysiology and }\end{array}$ & $\begin{array}{l}\text { Drafting/revision of the } \\
\text { manuscript for content, } \\
\text { including medical writing }\end{array}$ \\
& $\begin{array}{l}\text { Transplantation (DEPT), } \\
\text { University of Milan, Italy; }\end{array}$ & $\begin{array}{l}\text { Neurology Unit, Foundation } \\
\text { in the acquisition of data }\end{array}$ \\
& $\begin{array}{l}\text { IRCCS Ca' Granda Ospedale } \\
\text { Maggiore Policlinico, Milan, } \\
\text { Italy }\end{array}$
\end{tabular}

\begin{tabular}{ll}
\hline Minoo & Blood Transfusion Research Major role in the acquisition \\
Ahmadinejad, & Center (M.A.), High Institute of data \\
MD & for Research and Education \\
& in Transfusion Medicine, \\
& Tehran, Iran
\end{tabular}

Roberto Del Neuroscience Section, Dino Analysis or interpretation of Bo, BS Ferrari Centre, Department data of Pathophysiology and Transplantation (DEPT), University of Milan, Italy

\begin{tabular}{ll}
\hline Megi Meneri, & University of Milan, Italy; \\
MD, PhD & Neurology Unit, Foundation of data \\
& IRCCS Ca' Granda Ospedale \\
& Maggiore Policlinico, Milan, \\
& Italy
\end{tabular}

\begin{tabular}{lll}
\hline Giacomo & Neuroscience Section, Dino & Drafting/revision of the \\
Pietro Comi, & Ferrari Centre, Department & manuscript for content, \\
MD & of Pathophysiology and & including medical writing \\
& Transplantation (DEPT), & for content \\
& University of Milan, & \\
& Neuromuscular and Rare \\
& Diseases Unit, Department \\
& of Neuroscience, \\
& Fondazione IRCCS Ca' \\
& Granda Ospedale Maggiore \\
& Policlinico, Milan, Italy
\end{tabular}

Stefania Corti, Neuroscience Section, Dino Drafting/revision of the MD, PhD Ferrari Centre, Department of manuscript for content, Pathophysiology and including medical writing Transplantation (DEPT), for content University of Milan, Neurology Unit, Foundation IRCCS Ca' Granda Ospedale Maggiore Policlinico, Milan, Italy

\begin{tabular}{lll}
\hline Dario Ronchi, & Neuroscience Section, Dino & Drafting/revision of the \\
PhD & Ferrari Centre, Department & manuscript for content, \\
of Pathophysiology and & including medical writing \\
& Transplantation (DEPT), & for content; study concept \\
& University of Milan, & or design; and analysis or \\
& Neurology Unit, Foundation & interpretation of data \\
& IRCCS Ca' Granda Ospedale \\
& Maggiore Policlinico, Milan, \\
& Italy
\end{tabular}

\section{References}

1. Rosen DR, Siddique T, Patterson D, et al. Mutations in $\mathrm{Cu} / \mathrm{Zn}$ superoxide dismutase gene are associated with familial amyotrophic lateral sclerosis. Nature. 1993;362(6415): $59-62$. 
2. Saccon RA, Bunton-Stasyshyn RKA, Fisher EMC, Fratta P. Is SOD1 loss of function involved in amyotrophic lateral sclerosis? Brain. 2013;136(Pt 8) 2342-2358.

3. Andersen PM, Nilsson P, Ala-Hurula V, et al. Amyotrophic lateral sclerosis associated with homozygosity for an Asp90AL mutation in CuZn-superoxide dismutase. Nat Genet. 1995;10(1):61-66.

4. Sapp PC, Rosen DR, Hosler BA, et al. Identification of three novel mutations in the gene for $\mathrm{CuZn}$ superoxide dismutase in patients with familial amyotrophic lateral sclerosis. Neuromuscul Disord. 1995;5(5):353-357.
5. Alavi A, Nafissi S, Rohani M, et al. Genetic analysis and SOD1 mutation screening in Iranian amyotrophic lateral sclerosis patients. Neurobiol Aging. 2013;34(5):1516.e1-8.

6. Chadi G, Maximino JR, Jorge FMH, et al. Genetic analysis of patients with familial and sporadic amyotrophic lateral sclerosis in a Brazilian Research Center. Amyotroph Lateral Scler Frontotemporal Degener. 2017;18(3-4):249-255.

7. Kuźma-Kozakiewicz M, Andersen PM, Elahi E, et al. Putative founder effect in the Polish, Iranian and United States populations for the L144S SOD1 mutation associated with slowly uniform phenotype of amyotrophic lateral sclerosis. Amyotroph Lateral Scler Front Degener. 2021;22(1-2):80-85 


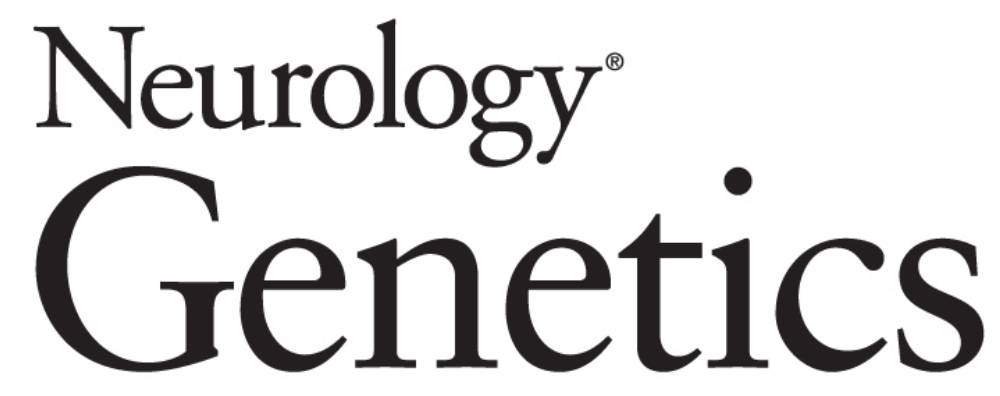
Homozygous SOD1 Variation L144S Produces a Severe Form of Amyotrophic Lateral Sclerosis in an Iranian Family
Delia Gagliardi, Minoo Ahmadinejad, Roberto Del Bo, et al.
Neurol Genet 2022;8;
DOI 10.1212/NXG.0000000000000645

This information is current as of December 16, 2021

\begin{abstract}
Updated Information \& Services

References

Subspecialty Collections

Permissions \& Licensing

Reprints

including high resolution figures, can be found at: http://ng.neurology.org/content/8/1/e645.full.html

This article cites 7 articles, 0 of which you can access for free at: http://ng.neurology.org/content/8/1/e645.full.html\#\#ref-list-1

This article, along with others on similar topics, appears in the following collection(s):

\section{Amyotrophic lateral sclerosis}

http://ng.neurology.org//cgi/collection/amyotrophic_lateral_sclerosis_

Information about reproducing this article in parts (figures,tables) or in its entirety can be found online at:

http://ng.neurology.org/misc/about.xhtml\#permissions

Information about ordering reprints can be found online: http://ng.neurology.org/misc/addir.xhtml\#reprintsus
\end{abstract}

Neurol Genet is an official journal of the American Academy of Neurology. Published since April 2015, it is an open-access, online-only, continuous publication journal. Copyright Copyright $\odot 2021$ The Author(s). Published by Wolters Kluwer Health, Inc. on behalf of the American Academy of Neurology.. All rights reserved. Online ISSN: 2376-7839.

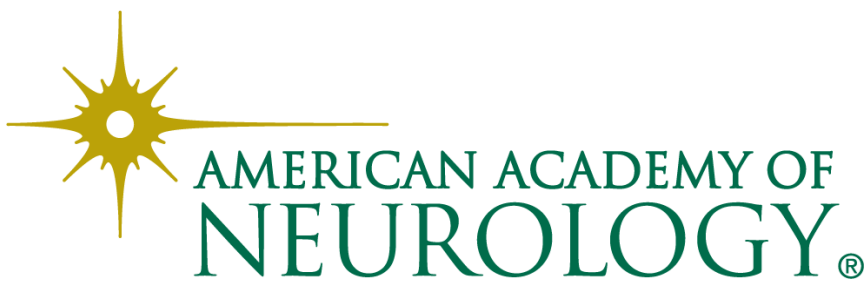

